\title{
CORRECTION
}

View Article Online

View Journal I View Issue

Check for updates

Cite this: New J. Chem., 2017 41,5225

DOI: 10.1039/c7nj90044a

rsc.li/njc

\section{Correction: Replacing bisphenol-A with bisguaiacol-F to synthesize polybenzoxazines for a pollution-free environment}

\author{
Thirukumaran Periyasamy, ${ }^{a}$ Shakila Parveen Asrafali, ${ }^{\mathrm{b}}$ Sarojadevi Muthusamy*b ${ }^{\text {and }}$ \\ Seong-Cheol Kim*a
}

Correction for 'Replacing bisphenol-A with bisguaiacol-F to synthesize polybenzoxazines for a pollutionfree environment' by Thirukumaran Periyasamy et al., New J. Chem., 2016, 40, 9313-9319.

The authors regret that the incorrect mass spectrum was supplied with their submission. Fig. 2 in the ESI has now been updated to show the correct spectrum.

The following corrections and clarifications are made to the main article:

\section{Abstract}

A solventless method was adopted for the synthesis of the benzoxazine monomers but not BGF.

\section{Introduction}

The authors regret their omission of ref. 1 to support their statement that: "Bisguaiacol-F (BGF) is considered as an alternative to BPA, as the structure of BGF is similar to that of BPA and it is incapable of interfering with hormones (estrogen), but retains the desirable thermal and mechanical properties of BPA."

Ref. 5 in the main article is replaced with ref. 2 below.

The authors correct the second sentence of paragraph 3 in the introduction to: "Guaiacol is a naturally occurring organic compound with the formula $\left(\mathrm{C}_{6} \mathrm{H}_{4}\right)(\mathrm{OH})\left(\mathrm{OCH}_{3}\right)$, discovered by Ascanio Sobrero.",3

\section{Experimental}

Section 2.2 should include the following description of the GC-MS system used: The JEOL GCMATE II GC-MS with Data system is a high resolution, double focusing instrument. Maximum resolution: 6000. Maximum calibrated mass: 1500 Daltons. Source options: Electron impact (EI); Chemical ionization (CI).

The procedure described in the synthesis of bisguaiacol-F is corrected to state that: The temperature was then raised to $150{ }^{\circ} \mathrm{C}$ and stirring was continued for $12 \mathrm{~h}$.

The original version of Scheme 2 contained an incorrect structure for furfurylamine, the corrected version is shown below.

\section{Results and discussion}

The final sentence of paragraph 3 in section 3.1 is corrected to: The mass spectrum of BGF (ESI 2, ESI) shows the molecular ion peak for BGF at $m / z=259$.

\footnotetext{
${ }^{a}$ School of Chemical Engineering, Yeungnam University, South Korea. E-mail: sckimo7@ynu.ac.kr

${ }^{b}$ Department of Chemistry, Anna University, Chennai, 600025, India. E-mail: msrde2000@yahoo.com
} 


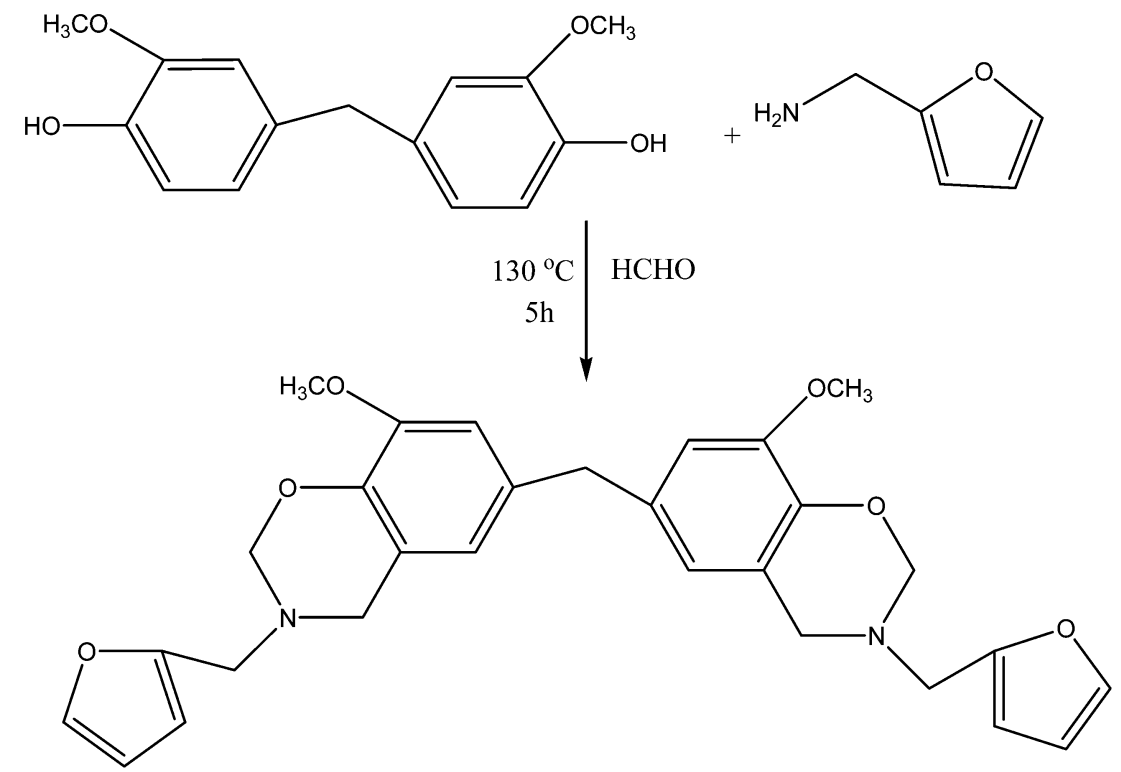

Scheme 2 Synthesis of benzoxazine monomer [BGF-FBz]

The Royal Society of Chemistry apologises for these errors and any consequent inconvenience to authors and readers.

\section{References}

1 https:/www.acs.org/content/acs/en/pressroom/newsreleases/2014/march/potentially-safer-greener-alternative-to-bpa-could-comefrom-papermaking-waste.html.

2 (a) E. D. Hernandez, A. W. Bassett, J. M. Sadler, J. J. La Scala and J. F. Stanzione, ACS Sustainable Chem. Eng., 2016, 4, 4328-4339; (b) H. Hong, B. G. Harvey, G. R. Palmese, J. F. Stanzione, H. W. Ng, S. Sakkiah, W. Tong and J. M. Sadler, Int. J. Environ. Res. Public Health, 2016, 13, 705-720.

3 http://www.derekclarke.com/services/guaiacol-cas-90-05-1/52. 